OPEN ACCESS

Edited by:

Shihua Wang,

Fujian Agriculture and Forestry

University, China

Reviewed by:

Miguel A. De la Cruz,

IMSS, Mexico

Yunlong Li,

Wadsworth Center, United States

*Correspondence:

Roy M. Robins-Browne

r.browne@unimelb.edu.au

${ }^{\dagger}$ These authors have contributed equally to this work

Specialty section: This article was submitted to

Infectious Diseases,

a section of the journal

Frontiers in Microbiology

Received: 02 May 2017

Accepted: 28 July 2017

Published: 11 August 2017

Citation:

Hodson C, Yang J, Hocking DM, Azzopardi K, Chen Q, Holien JK,

Parker MW, Tauschek M and Robins-Browne RM (2017) Control of Virulence Gene Expression by the Master Regulator, CfaD, in the Prototypical Enterotoxigenic Escherichia coli Strain, H10407.

Front. Microbiol. 8:1525.

doi: 10.3389/fmicb.2017.01525

\section{Control of Virulence Gene Expression by the Master Regulator, CfaD, in the Prototypical Enterotoxigenic Escherichia coli Strain, H10407}

\author{
Carla Hodson ${ }^{1 \dagger}$, Ji Yang ${ }^{1 \dagger}$, Dianna M. Hocking' ${ }^{1}$, Kristy Azzopardi',2, Qianyu Chen ${ }^{1}$, \\ Jessica K. Holien ${ }^{3}$, Michael W. Parker ${ }^{3,4}$, Marija Tauschek ${ }^{1}$ and \\ Roy M. Robins-Browne ${ }^{1,2 *}$ \\ ${ }^{1}$ Department of Microbiology and Immunology, Peter Doherty Institute for Infection and Immunity, The University of \\ Melbourne, Parkville, VIC, Australia, ${ }^{2}$ Murdoch Childrens Research Institute, The Royal Children's Hospital, Parkville, VIC, \\ Australia, ${ }^{3}$ Australian Cancer Research Foundation Rational Drug Discovery Centre, St. Vincent's Institute of Medical \\ Research, Fitzroy, VIC, Australia, ${ }^{4}$ Department of Biochemistry and Molecular Biology, Bio21 Molecular Science and \\ Biotechnology Institute, The University of Melbourne, Parkville, VIC, Australia
}

Enterotoxigenic Escherichia coli (ETEC) is the most common bacterial cause of diarrhea in children in developing countries, as well as in travelers to these countries. To cause disease, ETEC needs to produce a series of virulence proteins including enterotoxins, colonization factors and secretion pathways, which enable this pathogen to colonize the human small intestine and deliver enterotoxins to epithelial cells. Previously, a number of studies have demonstrated that $\mathrm{CfaD}$, an AraC-like transcriptional regulator, plays a key role in virulence gene expression by ETEC. In this study, we carried out a transcriptomic analysis of ETEC strain, H10407, grown under different conditions, and determined the complete set of genes that are regulated by CfaD. In this way, we identified a number of new target genes, including rnr-1, rnr-2, etpBAC, agn43, flu, traM and ETEC_3214, whose expression is strongly activated by $\mathrm{CfaD}$. Using promoter-lacZ reporters, primer extension and electrophoretic mobility shift assays, we characterized the CfaD-mediated activation of several selected target promoters. We also showed that the gut-associated environmental signal, sodium bicarbonate, stimulates CfaD-mediated upregulation of its virulence target operons. Finally, we screened a commercial small molecule library and identified a compound $(\mathrm{CH}-1)$ that specifically inhibited the regulatory function of $\mathrm{CfaD}$, and by 2-D analoging, we identified a second inhibitor $(\mathrm{CH}-2)$ with greater potency.

Keywords: enterotoxigenic E. coli, CfaD regulon, virulence genes, transcriptional regulation, virulence inhibition

\section{INTRODUCTION}

Enterotoxigenic Escherichia coli (ETEC) is a leading cause of acute diarrhea in infants in developing countries and in travelers to these countries (Al-Abri et al., 2005; Paschke et al., 2011; Kotloff et al., 2013). The virulence hallmark of this pathogen is the ability to produce either one or both of two well-characterized enterotoxins: heat-labile (LT) and heat-stable (ST) enterotoxins (Croxen and Finlay, 2010). For successful infection, ETEC also requires the assistance of colonization factors, such as CFA/I, which allow the pathogen to adhere to the small intestinal epithelium 
(Gaastra and Svennerholm, 1996; Fleckenstein et al., 2010). The CFA/I fimbriae of the ETEC strain, H10407, are encoded by the $c f a A B C E$ operon, which is positively controlled by the transcriptional regulator, CfaD (Caron and Scott, 1990). In ETEC strains that produce CS1 or CS2 fimbriae (encoded by the cooBACD operon), the Rns protein (a CfaD homolog) activates their transcriptional expression (Caron et al., 1989). CfaD/Rns also activate the expression of CS4, CS14, CS17, and CS19 (Bodero and Munson, 2016). Collectively, ETEC strains bearing these fimbriae constitute approximately $80 \%$ of human isolates.

$\mathrm{CfaD}$ and Rns are members of the AraC family of transcriptional regulators and is closely related to other virulence regulators such as AggR from enteroaggregative E. coli (Nataro et al., 1994; Gallegos et al., 1997), ToxT from Vibrio cholerae (DiRita et al., 1991), RegA from Citrobacter rodentium (Yang et al., 2009) and VirF from Shigella species (Dorman, 1992). CfaD is a protein of 265 amino acids whose carboxy-terminal domain contains two helix-turn-helix (HTH) DNA-binding motifs. The amino-terminal domain of ToxT and RegA is implicated in dimerization and cofactor binding, but the function of the corresponding region of $\mathrm{CfaD}$ is unknown.

The promoter regions of the operons controlled by these regulatory proteins are generally AT-rich and exhibit a high degree of intrinsic DNA curvature (Dorman, 2007; Yang et al., 2011). The global regulator, H-NS, is able to bind to these sequences and silence their expression by blocking access of RNA polymerase to the promoters (Dorman, 2007; Yang et al., 2011). As with other AraC-like virulence regulators, $\mathrm{CfaD}$ activates transcription of its target operons by binding to asymmetrical, highly AT-rich sequences and displacing $\mathrm{H}-\mathrm{NS}$ from the promoters (Gallegos et al., 1997). In addition to activating the cfaABCE operon, CfaD also activates the transcription of its own gene, and the cexE gene, which encodes a secreted protein homologous to the Aap dispersin of enteroaggregative E. coli (Pilonieta et al., 2007). Furthermore, CfaD also acts as a repressor of $n l p$, which encodes an inner membrane lipoprotein (Bodero et al., 2007). Although several studies have investigated CfaDmediated regulation of specific target genes, no comprehensive characterization of the entire $\mathrm{CfaD}$ regulon has been carried out. In this study, we performed RNAseq transcriptomic analysis of the prototypical ETEC strain, H10407, and identified and characterized a number of previously unknown members of the $\mathrm{CfaD}$ regulon. The critical importance of $\mathrm{CfaD}$ in the control of ETEC virulence makes it a potential target for new types of drugs that could be used to prevent or treat ETEC infections. To test this possibility, we screened small molecule libraries for CfaD-specific inhibitors.

\section{MATERIALS AND METHODS}

\section{Bacterial Strains, Plasmids, Primers and Media}

The bacterial strains and plasmids used in this study are listed in Table 1, and the primers are listed in Table 2. Bacteria were grown at $37^{\circ} \mathrm{C}$ in Luria-Bertani broth (LB) or on Luria-Bertani agar (LA) plates supplemented with antibiotics, when needed, at the following concentrations: ampicillin, $100 \mu \mathrm{g} / \mathrm{ml}$; kanamycin, $50 \mu \mathrm{g} / \mathrm{ml}$; trimethoprim, $40 \mu \mathrm{g} / \mathrm{ml}$; chloramphenicol, $25 \mu \mathrm{g} / \mathrm{ml}$.

\section{DNA Manipulation Techniques}

Restriction enzyme digestions were performed using enzymes and buffers from New England BioLabs (NEB) according to the manufacturer's instructions. DNA sequencing was performed using the BigDye terminator (v3.1) cycle sequencing kit (Applied Biosystems) in accordance with the manufacturer's instructions. Sequencing reactions were completed in a GeneAmp PCR system 9700 thermal cycler (Applied Biosystems). Analysis of sequencing results was achieved using the Sequencher (Gene Codes) and DNA Strider ${ }^{1}$ programs. PCR amplifications were performed using GoTaq Green Master Mix (Promega), or Phusion Flash High-Fidelity PCR Master Mix (Finnzymes). PCR primers (Table 2) were obtained from GeneWorks (Australia) or Bioneer Pacific. To construct the plasmids used in this study, we first cloned the various PCR fragments into pCR2.1-TOPO (Invitrogen/Life Technologies) or pGEM-T Easy (Promega). Following sequence verification, we cloned the various inserts from the pCR2.1-TOPO or pGEM-T Easy derivatives into the appropriate vectors (Table 1). To scramble the $\mathrm{CfaD}$ boxes in the regulatory regions of the $r n r-1$, etp $B$, ETEC_3214 genes, we used the Q5 site-directed mutagenesis kit (New England Biolabs).

\section{Construction of $\triangle c f a D$ and $\triangle c f a A B C E$ Knockout Mutants of E. coli H10407}

The $\lambda$ Red recombinase system (Datsenko and Wanner, 2000) was used to construct a $c f a D$ knockout mutation in ETEC strain, H10407. First, the Phusion high-fidelity DNA polymerase, the primer pairs, cfaDkoF/cfaDkoR, and plasmid, pKD4, were used in a PCR reaction to generate a DNA fragment that contains the kanamycin-resistance gene cassette $\left(\mathrm{Kan}^{\mathrm{R}}\right)$ flanked by 50 -bp DNA sequences corresponding to the upstream and downstream regions of the $c f a D$ gene. This linear DNA fragment was then transformed by electroporation into E. coli H10407, which carried plasmid pKD46, encoding the $\lambda$ Red recombinase system. The resultant $\Delta c f a D:: \mathrm{kan}^{\mathrm{R}}$ mutant was confirmed by PCR using primer pairs pKD4Fs/CfaDseqR and pKD4Rs/CfaDseqF.

The same method was also used to construct $\triangle c f a A B C E:$ :kan mutant except that primers $c f a A k o F$ and cfaEkoR were used to generate the $\mathrm{Kan}^{\mathrm{R}}$ flanked by DNA sequences of upstream and downstream regions of the $c f a A B C E$ gene cluster. Primer pairs cfaAseqF/pKD4Rs, and pKD4Fs/cfaEseqR were used to confirm the $\triangle c f a A B C E::$ kan mutation in H10407.

\section{RNAseq Analysis}

Overnight cultures of E. coli H10407 $\Delta c f a D(p A C Y C 184)$ and $\mathrm{H} 10407 \Delta c f a D(\mathrm{pACYC} 184-\mathrm{CfaD})$ were diluted 1 in 100 in LB with $25 \mu \mathrm{g} / \mathrm{ml}$ chloramphenicol, with or without $45 \mathrm{mM}$ bicarbonate, and incubated at $37^{\circ} \mathrm{C}$ with shaking to an $\mathrm{OD}_{600}$ of approximately 0.8. Two volumes of RNAprotect (Qiagen) were added to one volume of culture, and the samples were incubated at room temperature for $10 \mathrm{~min}$. They were then

${ }^{1}$ http://cellbiol.com/soft.htm 
TABLE 1 | Strains and plasmids used in this study.

\begin{tabular}{|c|c|c|}
\hline Strains/plasmids & Relevant characteristics & Source \\
\hline \multicolumn{3}{|c|}{ Escherichia coli strains } \\
\hline $\mathrm{H} 10407$ & Prototypical ETEC strain, O78:H11 & Skerman et al., 1972 \\
\hline $\mathrm{H} 10407 \Delta c f a D$ & $\Delta c f a D:: K^{R}{ }^{R}$ & This study \\
\hline $\mathrm{H} 10407 \triangle \mathrm{cfaABCE}$ & $\triangle c f a A B C E:: K^{R}{ }^{R}$ & This study \\
\hline MC4100 & $\mathrm{F}^{-}$araD139 (argF-lac) lacU169 rpsL150 relA1 $\Delta b B 5301$ deoC1 ptsF25 rbsR thiA & Casadaban, 1976 \\
\hline BL21(DE3) & $\mathrm{F}^{-}$ompT gal dcm lon hsd $S_{B}\left(r_{B}{ }^{-} m_{B}^{-}\right) \lambda\left(\right.$ DE3 [lacl lacUV5-T7p07 ind1 sam7 nin5]) $\left[m_{a l B^{+}}\right]_{K-12}\left(\lambda^{S}\right)$ & NEB \\
\hline TOP10 & $\begin{array}{l}\mathrm{F}^{-} \text {mcrA } \Delta\left(\mathrm{mrr}^{-}, \text {hsdRMS }\right. \\
\Delta(\text { ara-leu }) 7697 \text { galE15 galK16 rpsL }\left(\mathrm{Str}^{\mathrm{R}}\right) \text { end } A 1 \lambda^{-}\end{array}$ & Invitrogen \\
\hline JP8042 & $\Delta$ lacU169 recA56 tyrR366 & Yang et al., 2013 \\
\hline \multicolumn{3}{|l|}{ Plasmids } \\
\hline pGEM-T Easy & High-copy number vector, $A p^{R}$ & Promega \\
\hline pCR2.1-TOPO & High-copy number vector, $A p^{R}, K{ }^{R}{ }^{R}$ & Invitrogen \\
\hline pACYC184 & Medium-copy number vector, $\mathrm{Cm}^{\mathrm{R}}, \mathrm{Tc}^{\mathrm{R}}$ & Chang and Cohen, 1978 \\
\hline pKD4 & Vector containing $\operatorname{Kan}^{R}$ gene, $\operatorname{Kan}^{R}, A p^{R}$ & Datsenko and Wanner, 2000 \\
\hline pKD46 & Low-copy number vector, $P_{B A D}-\lambda$ Red, $A p^{R}$ & Datsenko and Wanner, 2000 \\
\hline pMU2385 & Single-copy number transcriptional fusion vector, $\mathrm{Tp}^{\mathrm{R}}$ & Yang et al., 2004 \\
\hline pMAL-c2x & Expression vector for $\mathrm{N}$-terminal MBP-fusion protein, $A p^{R}$ & NEB \\
\hline pACYC184-CfaD & pACYC184 carrying the $c f a D$ gene, $\mathrm{Cm}^{\mathrm{R}}$ & This study \\
\hline pMAL-c2x-CfaD & pMAL-c $2 x$ carrying the $c f a D$ coding region, $A p^{R}$ & This study \\
\hline$r n r-1-l a c Z(A)$ & rnr-1 promoter region in pMU2385, $\mathrm{Tp}^{\mathrm{R}}$ & This study \\
\hline$r n r-1-l a c Z(B)$ & rnr-1 promoter region in $\mathrm{pMU} 2385, \mathrm{Tp}^{\mathrm{R}}$ & This study \\
\hline $\operatorname{etp} B-\operatorname{lac} Z(A)$ & etpB promoter region in $\mathrm{pMU} 2385, \mathrm{Tp}^{\mathrm{R}}$ & This study \\
\hline $\operatorname{etpB-lacZ}(\mathrm{B})$ & etpB promoter region in pMU2385, $\mathrm{Tp}^{\mathrm{R}}$ & This study \\
\hline ETEC_3214-lacZ (A) & ETEC_3214 promoter region in pMU2385, TpR & This study \\
\hline ETEC_3214-lacZ (B) & ETEC_3214 promoter region in pMU2385, TpR & This study \\
\hline
\end{tabular}

centrifuged at $4000 \times g$ for $20 \mathrm{~min}$. RNA was extracted using the FastRNA Pro Blue Kit (QBiogene) according to the manufacturer's instructions, except that after the addition of chloroform, $350 \mu \mathrm{l}$ of the upper phase were added to $35 \mu \mathrm{l}$ sodium acetate in $875 \mu \mathrm{l}$ cold $100 \%$ ethanol, and held at $-20^{\circ} \mathrm{C}$ overnight. The samples were then centrifuged at $4000 \times g$ for $15 \mathrm{~min}$ at $4^{\circ} \mathrm{C}$, after which the supernatants were removed and the pellets were left to air dry for approximately $45 \mathrm{~min}$ before being resuspended in $87.5 \mu \mathrm{l}$ nuclease-free water. Samples were treated with $2.5 \mu \mathrm{l}$ DNase I and $10 \mu \mathrm{l}$ RDD buffer from the RNase-Free DNase Set (Qiagen). Following a purification using the RNeasy MinElute cleanup kit (Qiagen), the samples were eluted in $34 \mu \mathrm{l}$ of RNase-free water. RNA quality and integrity were examined using an Agilent Bioanalyzer before subjecting samples to rRNA depletion by using the Ribo-Zero ${ }^{\mathrm{TM}}$ Magnetic Kit (Gram-negative bacteria) (Epicenter) according to the manufacturer's instructions. The samples were then repurified using the RNeasy MinElute cleanup kit (Qiagen) with a final elution volume of $12 \mu \mathrm{l}$ in RNase-free water. RNA sequencing was performed at the Australian Genome Research Facility using an Illumina Hiseq 2000.

Raw data file reads were subjected to trimming of low-quality bases and removal of adapter sequences using Trimmomatic (v0.30) (Lohse et al., 2012). Trimmed reads were aligned to the H10407 genome (NCBI accession NC_017723.1) using Bowtie (Langmead et al., 2009). SAM files produced by Bowtie were converted to BAM files and coverage depth was calculated using
SAMtools ( $\mathrm{Li}$ et al., 2009) resulting in $>98 \%$ coverage across the genome with an average of $172 \times$ coverage (ranging between $110 \times$ and $211 \times$ depending on the sample). Aligned reads were then counted per gene in the ETEC H10407 genome using the HTSeq software suite. Data were analyzed by using the SPARTA program (Johnson et al., 2016). Differentially expressed genes were identified as those with an average normalized count $>100$, differential gene expression of $>4.5$-fold, and a $P$-value of $<0.05$. Supplementary Table $\mathbf{S} 1$ contains all the differential gene expression data generated in this study.

\section{$\beta$-Galactosidase Assay}

To examine the promoter functions and to evaluate the effect of the small molecule inhibitors on CfaD-mediated activation, cells were grown to mid-log phase $\left(\mathrm{OD}_{600} \sim 0.6\right)$, with or without shaking, respectively, after which $\beta$-galactosidase activity was assayed as described by Miller (1974), with specific activity expressed in units as described therein. Data are the means \pm SD of at least three independent assays.

\section{Expression and Purification of MBP::CfaD}

A DNA fragment, which contained the coding region of $c f a D$ and was flanked by HindIII and BamHI sites, was amplified by PCR using primer pairs MBPcfaD-F and MBPcfaD-R and genomic DNA from E. coli H10407. The amplified DNA fragment 
TABLE 2 | Primers used in this study.

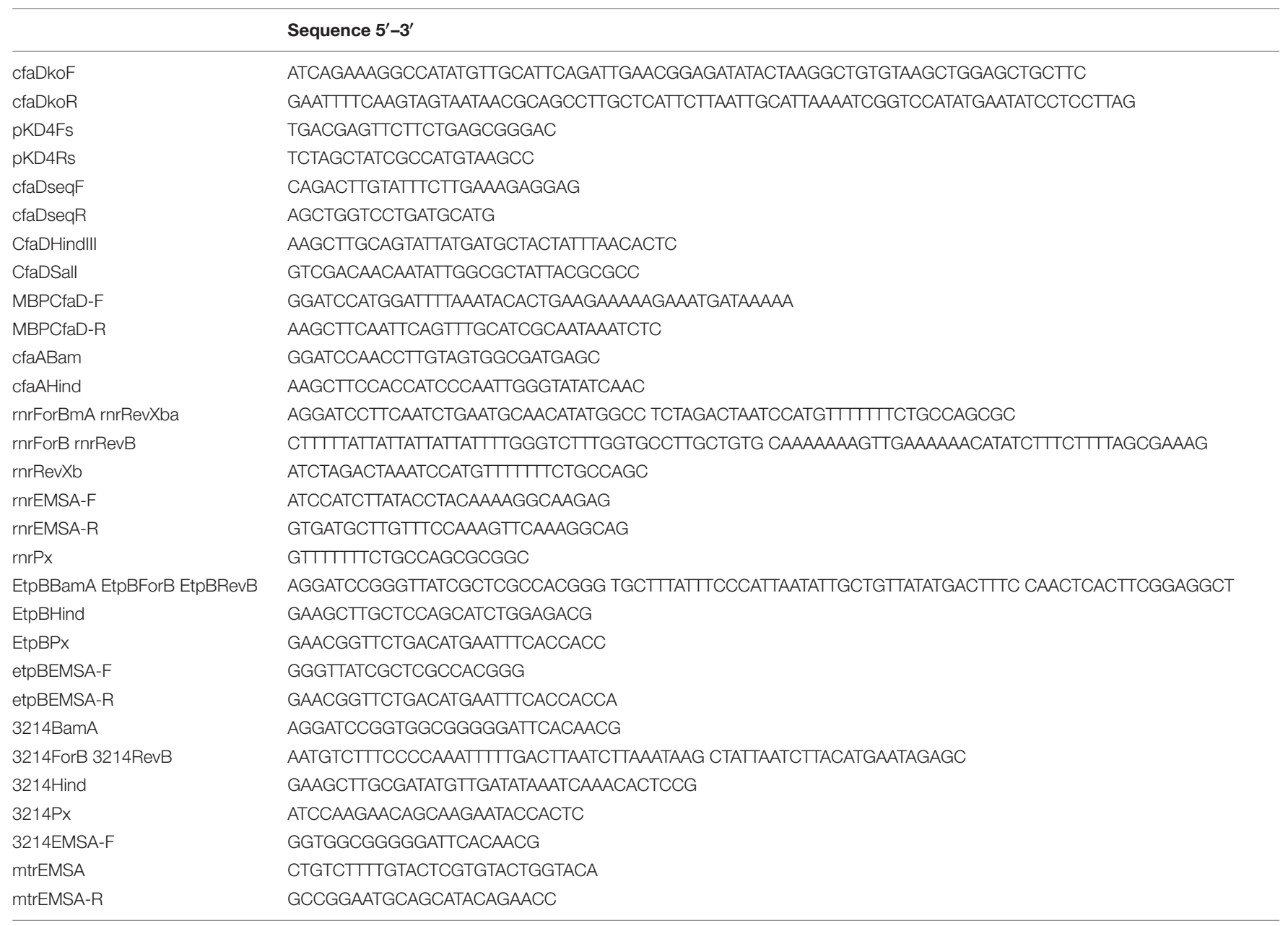

was cloned into TOPO-TA and sequenced. The $c f a D$ fragment was then excised and cloned into the HindIII and BamHI sites of pMAL-c2x (NEB) to create a fusion with the C-terminal end of the malE gene. The MBP::CfaD fusion protein was overexpressed and purified by using the methods described by the manufacturer. The concentration of purified MBP::CfaD protein was determined by using the Bradford method (Bradford, 1976).

\section{Electrophoretic Mobility Shift Assay (EMSA)}

The four ${ }^{32} \mathrm{P}$-labeled PCR fragments used in the EMSA were generated as follows. The primers rnrEMSA-R, etpBEMSA-R, $3214 \mathrm{Px}$ and mtrEMSA-R (Table 2) were labeled with ${ }^{32} \mathrm{P}$ at their $5^{\prime}$ end by using $\left[\gamma^{-32} \mathrm{P}\right]$-ATP and T4 polynucleotide kinase. The DNA fragments containing the promoter regions of $r n r$, etpB, ETEC_3214 and $m t r$ were each generated by PCR using primer pairs ${ }^{32} \mathrm{P}$-rnrEMSA-R /rnrEMSA-F, ${ }^{32} \mathrm{P}$-etpBEMSA-R/etpBEMSA-F, ${ }^{32} \mathrm{P}-3214 \mathrm{Px} / 3214 \mathrm{EMSA}-\mathrm{F}$ or ${ }^{32} \mathrm{P}$-mtrEMSA-R/mtrEMSA-F, respectively, with TOPO-TA carrying the $r n r$, etpB, ETEC_3214 or $m t r$ regulatory regions as template. Each end-labeled fragment was incubated with varying amounts of purified $\mathrm{MBP}: \mathrm{CfaD}$ protein at $37^{\circ} \mathrm{C}$ for
$30 \mathrm{~min}$ in the binding buffer (10 mM Tris. $\mathrm{HCl}$ [pH 7.4], $45 \mathrm{mM}$ $\mathrm{NaHCO}_{3}, 50 \mathrm{mM} \mathrm{KCl}, 1 \mathrm{mM}$ DTT, $100 \mu \mathrm{g} / \mathrm{ml} \mathrm{BSA}$, and $5 \mathrm{ng} / \mu \mathrm{l}$ poly(dI-dC)). Glycerol was added to a final concentration of $6.5 \%$. Samples were analyzed by electrophoresis on $5 \%$ native polyacrylamide gels $(37.5: 1)$. Electrophoresis was carried out at $4^{\circ} \mathrm{C}$ for approximately $12 \mathrm{~h}$ at $10 \mathrm{~V} / \mathrm{cm}$.

\section{Primer Extension Assay}

Primer extension was performed as follows. Total cellular RNA was purified from E. coli MC4100 derivatives containing pACYC184-CfaD and $r n$ r-1-lacZ-A, etpB-lacZ-A, ETEC_3214lac $Z$ - $A$ or pMU2385. Cells were grown to $\mathrm{OD}_{600} \sim 0.8$, and RNA was isolated by using the FastRNA Pro kit (MP Biomedicals) and RNA Miniprep Kit (Qiagen). ${ }^{32} \mathrm{P}$-labeled primers; ${ }^{32} \mathrm{P}$-rnrPx, ${ }^{32} \mathrm{P}$-EtpBPx and ${ }^{32} \mathrm{P}-3214 \mathrm{Px}$, were used to probe the start sites of transcription of the $r n r$, etpB and ETEC_3214 promoters, respectively. Each labeled primer was co-precipitated with $5 \mu \mathrm{g}$ of total RNA. Hybridization was carried out at $45^{\circ} \mathrm{C}$ for $15 \mathrm{~min}$ in $10 \mu \mathrm{l}$ of Tris-EDTA (TE) buffer containing $150 \mathrm{mM} \mathrm{KCl}$. Primer extension reactions were started by the addition of $24 \mu \mathrm{l}$ of extension solution (20 mM Tris- $\mathrm{HCl}$ [pH 8.4], $10 \mathrm{mM}$ $\mathrm{MgCl}_{2}, 10 \mathrm{mM}$ dithiothreitol [DTT], $2 \mathrm{mM}$ deoxynucleoside 
triphosphates [dNTPs], and $1 \mathrm{U} / \mu \mathrm{l}$ avian myeloblastosis virus [AMV] reverse transcriptase) and were carried out at $42^{\circ} \mathrm{C}$ for $60 \mathrm{~min}$. Samples were precipitated and then analyzed on a sequencing gel. GA ladders were generated by using the one-step method (Song et al., 1997).

\section{Screening Assay for Small Molecule Inhibitors of CfaD}

An overnight culture of test strain MC4100(cfaA-lacZ, pACYC184-CfaD) was diluted 1 in 100 in LB containing $45 \mathrm{mM} \mathrm{NaHCO}_{3}$ and then was dispensed in $100 \mu \mathrm{l}$ volumes into 96-well microtiter trays. Compounds $(5 \mu \mathrm{l}, 2 \mathrm{mM})$ from the Chembridge Microformats library (ChemBridge Corp.) were added to the wells in columns 2-11 of these test plates. The wells in columns 1 (used to determine the mean luminescence signal from untreated cells) and 12 (background) received $5 \mu \mathrm{l}$ of $100 \%$ DMSO alone. Control plates were filled with the same volume of compounds or DMSO alone and the control strain, E. coli JP8042(mtr-lacZ, pACYC177-TyrR), diluted (1:100) in $\mathrm{LB}$ broth containing $1 \mathrm{mM}$ tyrosine. The $m$ tr-lac $Z$ fusion is a house-keeping gene promoter reporter that is activated by TyrR (Yang et al., 1993). The inclusion of this control strain in the assay allowed us to filter out false-positives, such as compounds that inhibited bacterial growth or the $\beta$-galactosidase enzyme.

All samples were incubated at $37^{\circ} \mathrm{C}$ for $18 \mathrm{~h}$, after which $8 \mu \mathrm{l}$ of lysozyme (Sigma) solution $(6 \mathrm{mg} / \mathrm{ml})$ was added to the wells, followed by incubation at room temperature for another $20 \mathrm{~min}$. The $\beta$-galactosidase released from the bacterial cells was converted to a luminescence signal by adding $25 \mu \mathrm{l}$ of Beta-Glo (Promega) solution into the wells of columns 1-11. The level of luminescence from each well was measured 1.43, 2.86, and 4.3 min later using the FLUOStar Omega plate reader (BMG Labtech).

\section{Computational Modeling and Docking}

HHpred, a homology detection program which creates Hidden Markov Models (Soding et al., 2005), detected the ToxT crystal structure (PDB code 3GBG) (Lowden et al., 2010) as the closest homolog to the amino acid sequence of CfaD. A PIR alignment was generated from this crystal structure and submitted to MODELLER v 9.10 (Sali et al., 1995). The resulting CfaD homology model was then minimized sequentially (hydrogens, then side chains, and then main chains) under the Merck Molecular Force Field for 10,000 iterations and assessed using Procheck (Laskowski et al., 1993), which found that 99\% of the residues resided in the allowed regions of the Ramachandran plot. Chi1-Chi2 plots, main-chain parameters, side-chain parameters, G-factors, bond angles, and bond lengths were also all within the allowed parameters.

A SiteID search was conducted within Sybylx2.1 (Certara L.P.) to look for potential compound-binding pockets in the $\mathrm{CfaD}$ model. Docking protomols were created for each potential compound-binding pocket in Surflex, Sybyl 2.1 (Certara L.P.). For all the protomols the threshold was reduced to 0.32 and the bloat increased to $2 \AA$. The CfaD inhibitors, $\mathrm{CH}-1$ and $\mathrm{CH}-2$ were then docked into each protomol using the Surflex-Dock Geom mode in Sybylx2.1 (Certara L.P.). Flexibility of rings was allowed, but all other parameters were kept at default values. The top 30 scored solutions were retained and analyzed visually.

We have assembled a library of approximately 10 million commercially available compounds. Unity (Sybylx2.1, Certara L.P.) was used to conduct 2D analog searches of the hit compounds using a Tanimoto similarity of greater than 65\%. Compounds were then purchased and assayed. All figures were constructed using the PyMOL Molecular Graphics System, Version 1.8 Schrödinger, LLC.

\section{Analysis of CFA/I Fimbriae Production by H10407 in the Presence or Absence of CfaD Inhibitors}

To extract bacterial surface proteins, E. coli H10407 and its derivatives were grown in $10 \mathrm{ml}$ CFA medium (Evans et al., $1979)$ in the absence or presence of $\mathrm{CfaD}$ inhibitors $(25 \mu \mathrm{M}$ or $50 \mu \mathrm{M}), \mathrm{CH}-1$ and $\mathrm{CH}-2$, at $37^{\circ} \mathrm{C}$ for $6 \mathrm{~h}$ with shaking at $100 \mathrm{rpm}$. Cells were harvested by centrifugation at 3,000 $\times g$ for $10 \mathrm{~min}$, resuspended in $250 \mu \mathrm{l}$ of phosphate-buffered saline $(\mathrm{pH} 7.4)$, vortexed at high speed for $1 \mathrm{~min}$ and subsequently incubated at $60^{\circ} \mathrm{C}$ for $20 \mathrm{~min}$ with intermittent vortexing. The samples were then pelleted by centrifugation at $3,000 \times g$ for $10 \mathrm{~min}$, and the supernatant was transferred to a fresh tube, where it was mixed with NuPAGE lithium dodecyl sulfate sample reducing buffer (Thermo Scientific) and heated at $70^{\circ} \mathrm{C}$ for $10 \mathrm{~min}$. The samples $(25 \mu \mathrm{l})$ were then separated by SDS-PAGE using 12\% Bis-Tris NuPAGE gels (Invitrogen), and the separated proteins were stained with Coomassie brilliant blue G250. The bands of interest were excised, trypsin-digested, and analyzed by tandem mass spectrometry at the Proteomics Laboratory, Walter and Eliza Hall Institute of Medical Research, Melbourne, VIC, Australia.

\section{RESULTS}

\section{Transcriptomic Analysis of CfaD-Mediated Gene Regulation}

To measure differential gene expression in response to $\mathrm{CfaD}$ and screen the E. coli H10407 genome for previously unidentified genes that are regulated by $\mathrm{CfaD}$, RNAseq transcriptional profiling was performed on two $\mathrm{H} 10407 c f a D$ knockout mutants that carried either the control plasmid, pACYC184, or the CfaD-complementing plasmid, pACYC184-CfaD. Both CfaD homologs, RegA and ToxT, respond to bicarbonate ions in transcriptional activation of their target promoters (Abuaita and Withey, 2009; Yang et al., 2009). Accordingly, we tested the effect of bicarbonate ions on $\mathrm{CfaD}$-mediated activation by growing the $\mathrm{H} 10307$ derivatives in LB in the absence or presence of $45 \mathrm{mM}$ sodium bicarbonate.

The results showed that the transcription of 19 genes in 10 operons was markedly activated (between 5- and 550-fold) by $\mathrm{CfaD}$ in the presence of sodium bicarbonate (Figure 1). Three known targets of $\mathrm{CfaD}$, the $c f a A B C E$ and cexE-aatPABCD clusters, encoding CFA/I fimbriae, Aap dispersin-like protein 


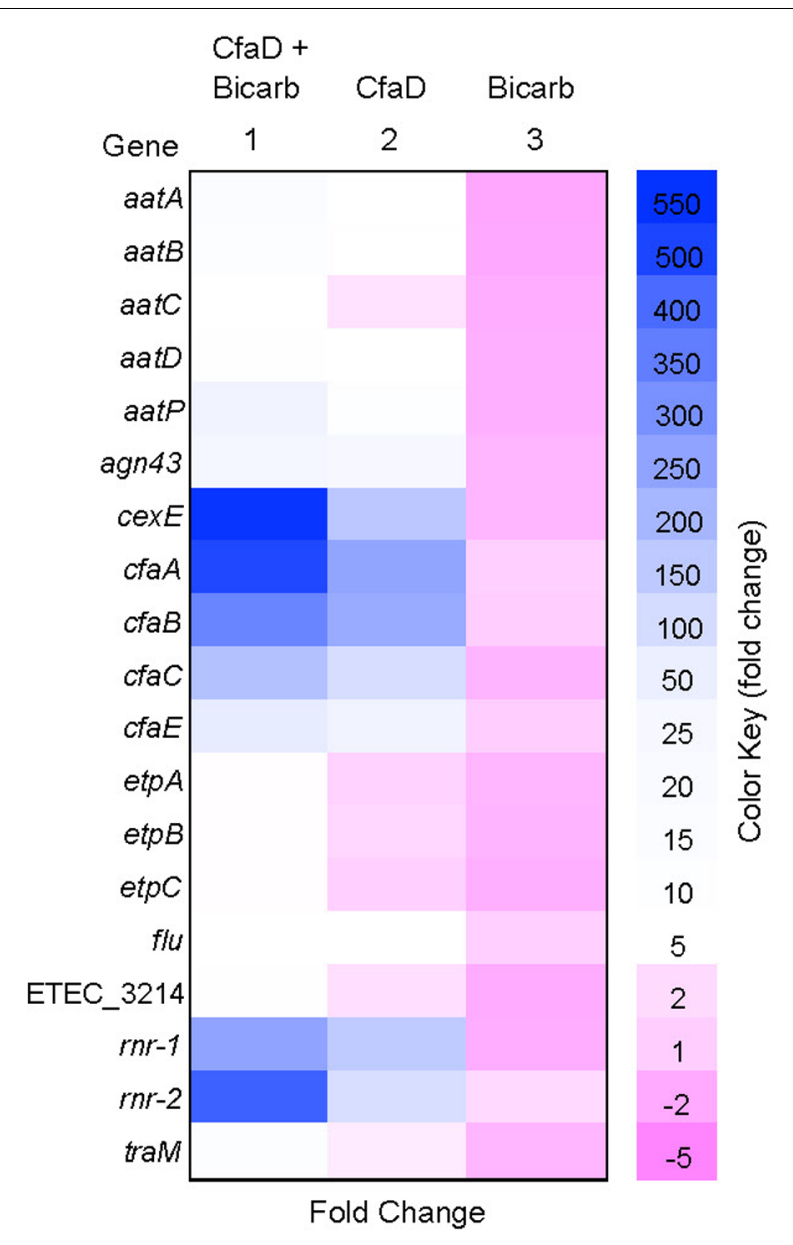

FIGURE 1 | Heat map showing the effects of $\mathrm{CfaD}$ and sodium bicarbonate on the expression of enterotoxigenic Escherichia coli (ETEC) genes. RNASeq data were used to determine fold changes in gene expression by comparing the number of transcripts from the following E. coli derivatives: $\mathrm{H} 10407 \mathrm{CfaD}^{+}$ grown with bicarbonate (column 1); $\mathrm{H} 10407 \mathrm{CfaD}^{+}$without bicarbonate (column 2), and $\mathrm{H} 10407 \mathrm{CfaD}^{-}$with bicarbonate (column 3), to those from $\mathrm{H} 10407 \mathrm{CfaD}^{-}$without bicarbonate. Negative and positive values represent the degrees of down- and up-regulation, respectively.

and its transport system, respectively, were highly upregulated by $\mathrm{CfaD}$. We also identified an additional 10 transcriptional units that were positively regulated by $\mathrm{CfaD}$. These included two copies of the $r n r$ gene ( $r n r-1$ and $r n r-2)$ encoding an

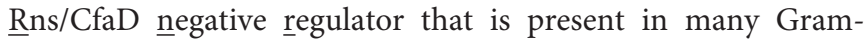
negative bacterial pathogens (Santiago et al., 2014); two copies of a gene encoding Antigen 43, annotated agn43 and flu (Owen et al., 1987; Crossman et al., 2010); the gene cluster etpBAC encoding an extracellular bridging adhesin (Roy et al., 2009); and the traM gene whose product is required for conjugation by $\mathrm{IncF}$ group plasmids (de la Cruz et al., 2010). An open reading frame, ETEC_3214, encoding a protein of unknown function was also strongly upregulated (Figure 1).

In the $\mathrm{CfaD}^{-}$background, sodium bicarbonate had no effect on the expression of the $\mathrm{CfaD}$-activated genes. In the $\mathrm{CfaD}^{+}$ strain, however, transcription of these genes was significantly enhanced by sodium bicarbonate (up to 4.6-fold; Figure 1). These results suggested that E. coli $\mathrm{H} 10407$ may use $\mathrm{CfaD}$ to sense and respond to bicarbonate ions in the small intestine, leading to increased levels of virulence gene expression.

\section{Further Analysis of Selected CfaD Target Promoters}

Analysis of the sequences of the newly identified CfaD target genes listed in Figure 1 using the Rns-binding site consensus sequence (Munson and Scott, 2000; Tan et al., 2011) revealed the likely $\mathrm{CfaD}$-binding sites within the vicinity of the promoter regions of the $r n r-1$ (and its copy, $r n r-2$ ), etpBAC and ETEC_3214 transcriptional units. To determine if these putative binding sites are required for $\mathrm{CfaD}$-mediated activation, we made two promoter-lacZ fusions for each of three transcriptional units: $r n r$-1, etpBAC and ETEC_3214 (Figure 2). In each pair, the lacZ fusion carrying the wild-type promoter fragment (construct $\mathrm{A}$ in Figure 2) contained a putative CfaD-binding site and the lacZ fusion carrying the mutant promoter fragment (construct B) had this sequence scrambled (Figure 2).

$\beta$-galactosidase assays showed that $\mathrm{CfaD}$ positively controls the expression of the three construct A promoters (Figure 2). In these cases, the $r n r-1, \operatorname{etp} B$ and ETEC_3214 promoters were upregulated 62-, 11-, and 5-fold, respectively, by $\mathrm{CfaD}$. In contrast, the three construct-B promoters exhibited various basal levels of transcription that were not enhanced by $\mathrm{CfaD}$ (Figure 2). These results are consistent with the hypothesis that the putative CfaD-binding sites identified in the promoter regions of these three operons are required for activation by $\mathrm{CfaD}$. The identification of the three new CfaD-binding sites allowed us to update the consensus sequence (Figure 4C).

\section{Direct Interaction of CfaD with the Regulatory Regions of $r n r-1$, etp $B$, and ETEC_3214}

To test if $\mathrm{CfaD}$ binds directly to the regulatory regions of $r n r-1$, etpBAC, and ETEC_3214, we performed electrophoretic mobility shift assays (EMSA). Previous studies have shown that $\mathrm{CfaD}$ is insoluble in water (Munson and Scott, 1999). To overcome this problem, we used a purified fusion protein (MBP::CfaD) for these assays. The three DNA fragments spanning the regulatory promoter-operator regions of $r n r-1$, etpB, and ETEC_3214, as well as a control fragment carrying the mtr regulatory region, were each end-labeled with ${ }^{32} \mathrm{P}$ and incubated with various concentrations of MBP::CfaD. The samples were then analyzed on native polyacrylamide gels. As shown in Figure 3, a concentration-dependent formation of CfaD-DNA complexes was detected with $r n r-1$, etpB, and ETEC_3214 promoter fragments, but not with the control DNA. These results showed that $\mathrm{CfaD}$ activates these three gene targets through a direct interaction with their respective regulatory regions.

\section{Identification of Transcriptional Start Sites of $r n r-1$, etpB, and ETEC-3214}

The transcriptional start sites associated with the $r n r-1, \operatorname{etp} B$, and ETEC_3214 promoters, were determined by using primer 


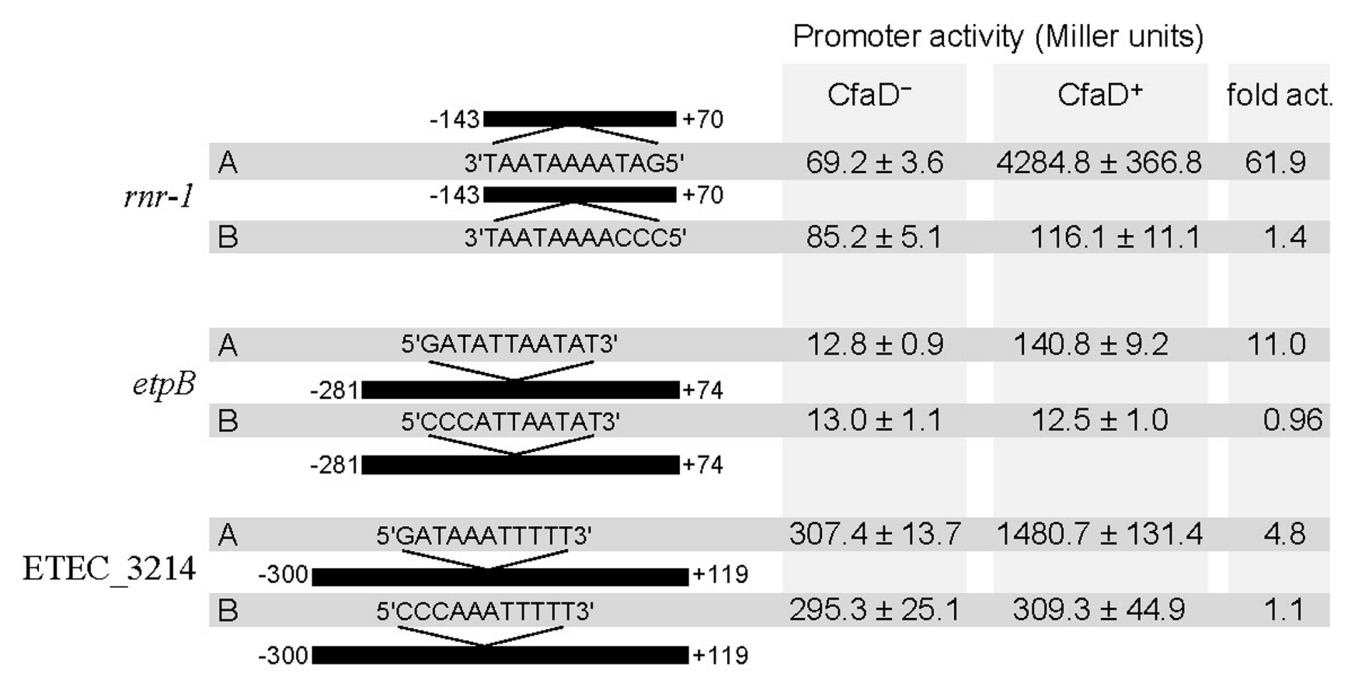

FIGURE 2 | $\beta$-galactosidase expression by constructs A and B of the rnr-1, etpB, and ETEC_3214 promoter-lac Z fusions in CfaD- and CfaD+ backgrounds, MC4100(pACYC184) and MC4100(pACYC184-CfaD), respectively. Numbering of the various promoter fragments is relative to their start site of translation. The sequences of $\mathrm{CfaD}$ boxes in constructs A of $r n r-1$, etpB, and ETEC_3214 and the base changes introduced into the CfaD boxes in constructs B are shown. $\beta$-galactosidase activity is expressed as Miller units, and the values are means plus standard deviations from three independent assays. The fold activation (fold act.) is the ratio of $\beta$-galactosidase activity of the $\mathrm{CfaD}^{+}$strain to that of the $\mathrm{CfaD}^{-}$strain.

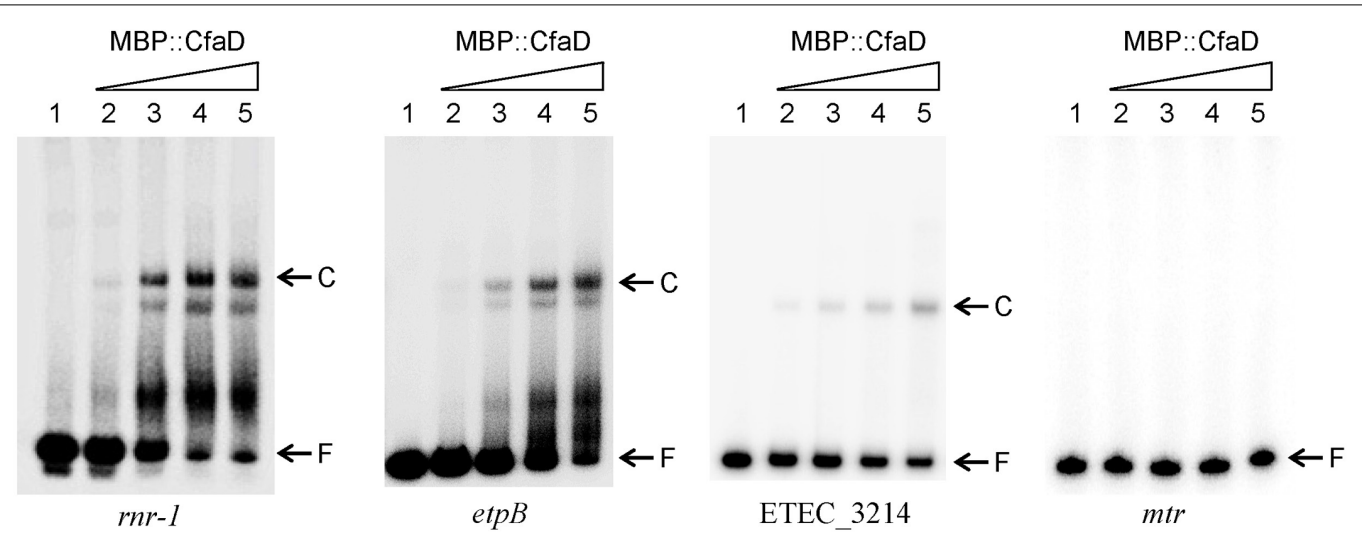

FIGURE 3 | Electrophoretic mobility shift assay demonstrating the binding of MBP::CfaD to the rnr-1, etpB, and ETEC_3214 promoters. Each ${ }^{32}$ P-labeled PCR fragment was incubated for $30 \mathrm{~min}$ at $30^{\circ} \mathrm{C}$ with increasing amounts of MBP::CfaD $(0,37.5,75$, 150, or $300 \mathrm{nM} \mathrm{MBP::CfaD} \mathrm{in} \mathrm{lanes} \mathrm{1-5,} \mathrm{respectively),} \mathrm{after} \mathrm{which}$ the samples were analyzed on native polyacrylamide gels. Bands of free DNA (F) and the major DNA-protein complexes (C) are indicated at the right of the gels. The mtr promoter fragment was used as a negative control in this assay.

extension. Briefly, three derivatives of E. coli MC4100 carrying pACYC184-CfaD and construct A of $r n r-1-l a c Z$, etpB-lacZ or ETEC_3214-lacZ (Figure 2) were grown to mid-log phase, after which total RNA was extracted. ${ }^{32} \mathrm{P}$-labeled primers were then used to probe the transcriptional start sites of the three transcriptional units. The results showed that in each case one major extension signal was observed (Figure 4A), indicating that these three operons are each driven by a single promoter. The transcriptional start sites corresponded to positions 31-, 108-, and 61-bp upstream of the start codons of the $r n r-1$, etpB and ETEC3214 coding sequences, respectively. Based on the position of the start sites of transcription, putative -35 and -10 regions of the three promoters were identified (Figure 4B).

\section{Screening for Chemical Inhibitors of CfaD}

To investigate the feasibility of $\mathrm{CfaD}$ as a drug target, we screened the Chembridge Microformat library (ChemBridge Corp.) for small molecule compounds that inhibited the ability of $\mathrm{CfaD}$ to activate expression of the $c f a A$ promoter. After screening approximately 20,000 compounds, we identified 63 compounds that showed various degrees of inhibition on $\mathrm{CfaD}$ mediated activation of $c f a A$ expression. However, following further tests, only one compound, which we named $\mathrm{CH}-1$, reproducibly exhibited a complete inhibition of $\mathrm{CfaD}$ function at the concentration of $100 \mu \mathrm{M}$. 


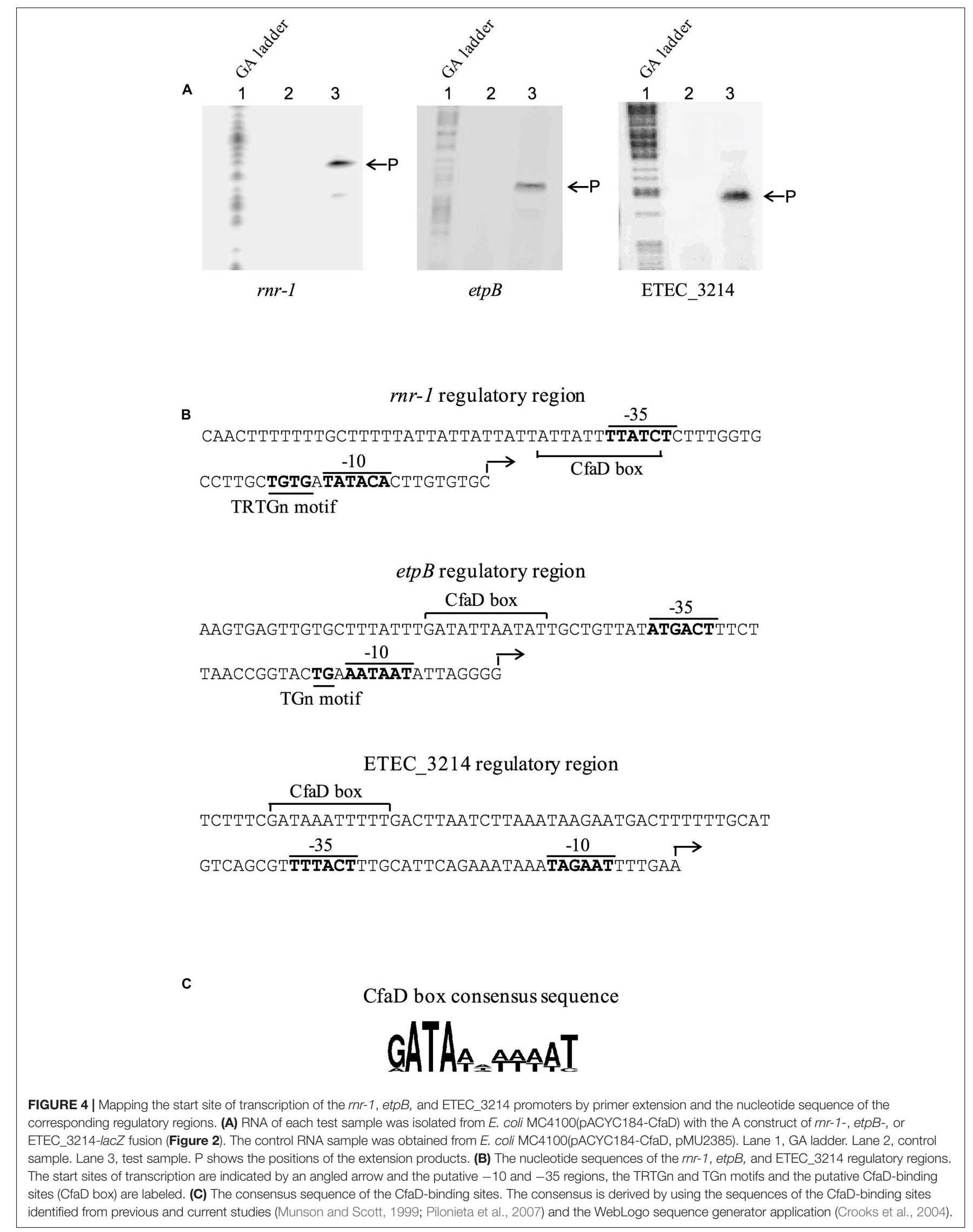




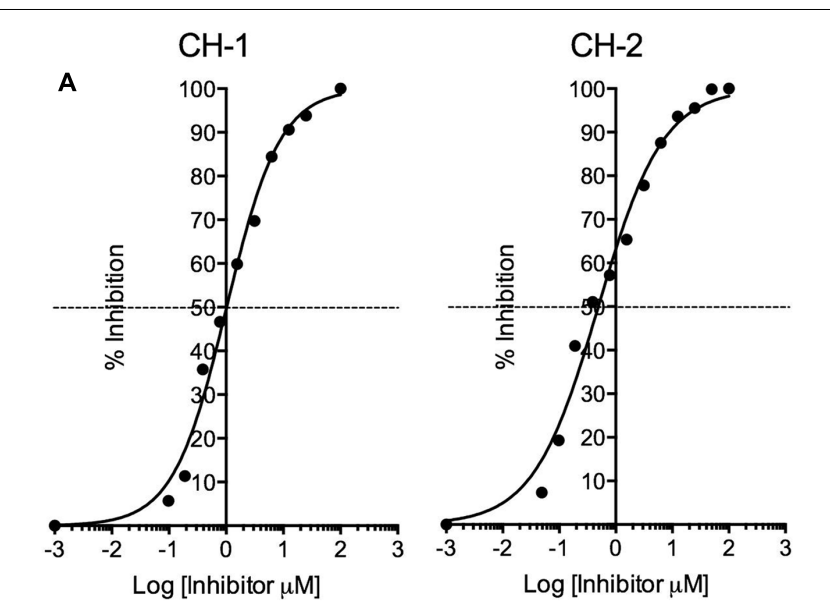

B

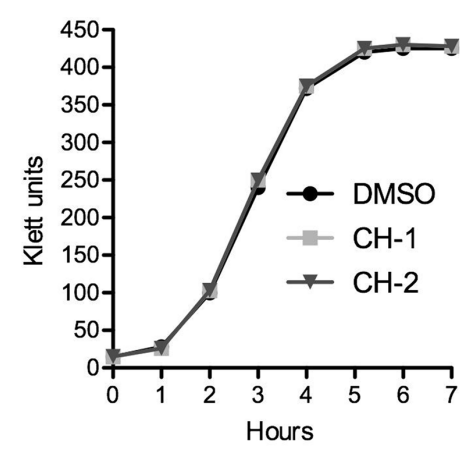

FIGURE 5 | Potency of small molecule inhibitors of CfaD. (A) The $\mathrm{IC}_{50}$ values of $\mathrm{CH}-1$ and $\mathrm{CH}-2$ were determined using dose-response curves. Data were obtained by measuring the $\beta$-galactosidase activities of the $E$. coli strain MC4100(cfaA-lacZ, pACYC184-CfaD) grown in the presence of varying concentrations of $\mathrm{CH}-1$ and $\mathrm{CH}-2$, and then used to calculate the $\mathrm{IC}_{50}$ (Sigmoidal dose-response equation, GraphPad Prism 5). (B) E. coli H10407 was grown at $37^{\circ} \mathrm{C}$ in LB broth with shaking (250 rpm) in the absence or presence of $\mathrm{CH}-1$ or $\mathrm{CH}-2(100 \mu \mathrm{M})$. Bacterial growth was followed using a Klett colorimeter over a period of $6 \mathrm{~h}$.

Using $\mathrm{CH}-1$, we then computationally screened our in-house virtual library of $\sim 10$ million chemicals for 2-D analogs of $\mathrm{CH}-1$. Thirty-two analogs were identified and tested for their ability to inhibit $\mathrm{CfaD}$ activity at the $c f a A$ promoter. We identified several compounds with varying activity, but only one of these analogs, which we named $\mathrm{CH}-2$, exhibited greater potency than $\mathrm{CH}-1$. As shown in Figure $\mathbf{5 A}$, the $\mathrm{IC}_{50}$ concentrations for $\mathrm{CH}$ 1 and $\mathrm{CH}-2$ are 1.02 and $0.49 \mu \mathrm{M}$, respectively. To verify that these two compounds did not inhibit bacterial growth, E. coli $\mathrm{H} 10407$ was grown in the absence or presence of $\mathrm{CH}-1$ and $\mathrm{CH}-2$ $(100 \mu \mathrm{M})$, and no differences in growth or viability were observed (Figure 5B).

We next examined the effect of $\mathrm{CH}-1$ and $\mathrm{CH}-2$ on CfaD-mediated activation of the $r n r-1$, etp $B$ and ETEC3214 promoters. E. coli MC4100 strains carrying construct A of $r n$-1-lacZ, etpB-lacZ or ETEC_3214-lacZ (Figure 2) and either pACYC184 (control) or pACYC184-CfaD (test) were grown in the absence or presence of $\mathrm{CH}-1$ and
CH-2 $(50 \mu \mathrm{M})$, following which $\beta$-galactosidase assays were performed. Data in Figure 6 showed that, while neither of the inhibitors had any effect on the basal level transcription of the three promoters in the $\mathrm{CfaD}^{-}$background (control), both $\mathrm{CH}-1$ and $\mathrm{CH}-2$ strongly inhibited CfaD-mediated activation of the three promoters in the $\mathrm{CfaD}^{+}$background (test).

\section{Characterization of the Interaction of $\mathrm{CH}-1$ and $\mathrm{CH}-2$ with $\mathrm{CfaD}$}

To explore the interactions of $\mathrm{CH}-1$ and $\mathrm{CH}-2$ with $\mathrm{CfaD}$, we performed an in silico docking experiment. A putative 3-D model of $\mathrm{CfaD}$ was generated based on the crystal structure of the ToxT protein of $V$. cholerae (Lowden et al., 2010). We used this model to identify three potential ligand-binding pockets. These sites were all over $10 \AA^{3}$ and accessible to the surface of the protein. $\mathrm{CH}-1$ and $\mathrm{CH}-2$ were docked into all three pockets. Analysis of the generated docking scores (related to the binding energy of interaction) and degrees of clustering in each pocket (a measure of the likelihood of a specific orientation) (Figure 7A) favored one of the pockets (pocket 2) over the rest, and correlated with the greater potency of $\mathrm{CH}-2$ (Figure 5A). This pocket is located between the putative dimerization site and the DNA-binding domain, and contains residues Lys85, Ile90, Ile91, Tyr92, Gly93, Met94, Ser95, Ile97, Asp98, Thr99, Arg103, Glu145, Glu148, Ile154, Ile156, Ser157, and Ser158 (Figure 7B). Both $\mathrm{CH}-1$ and $\mathrm{CH}-2$ were found to cluster predominantly in this pocket, with a similar orientation and convincing docking scores (Figure 7A).

\section{Confirmation of the Inhibitory Activity of $\mathrm{CH}-1$ and $\mathrm{CH}-2$ on Production of the CFA/I Fimbriae in E. coli H10407}

To examine effect of the inhibitors, $\mathrm{CH}-1$ and $\mathrm{CH}-2$, on CfaD-mediated expression of the CFA/I fimbriae in E. coli $\mathrm{H} 10407$, we carried out a proteomic analysis using the following E. coli strains: wild-type H10407, H10407 $\Delta c f a D$ (pACYC184$\mathrm{CfaD})$ and two negative controls, H10407 $\triangle \mathrm{cfaABCE}$ and $\mathrm{H} 10407 \Delta c f a D$ (pACYC184). Analysis of heat-extracted surface proteins using SDS-PAGE showed that a protein of approximately $17-\mathrm{kDa}$ was produced in the $\mathrm{H} 10407$ and $\mathrm{H} 10407 \Delta c f a D(\mathrm{pACYC184-CfaD})$ strains, but not in the $\mathrm{H} 10407 \triangle c f a A B C E$ and the H10407 $\Delta c f a D$ (pACYC184) strains (Figure 7C). Mass spectroscopic analysis revealed that the $17-\mathrm{kDa}$ protein was $\mathrm{CfaB}$, the major subunit of CFA/I fimbriae. These results confirmed the dependency of CFA/I expression on $\mathrm{CfaD}$ in $\mathrm{H} 10407$. Importantly, the data in lanes 5-8 (Figure 7C) demonstrated that the $\mathrm{CfaD}$-dependent production of $\mathrm{CfaB}$ in $\mathrm{H} 10407$ was strongly inhibited in the presence of $\mathrm{CH}-1$ or $\mathrm{CH}-2$.

\section{DISCUSSION}

Transcriptomic analyses performed in this study revealed the entire set of operons whose expression is activated by $\mathrm{CfaD}$ in 

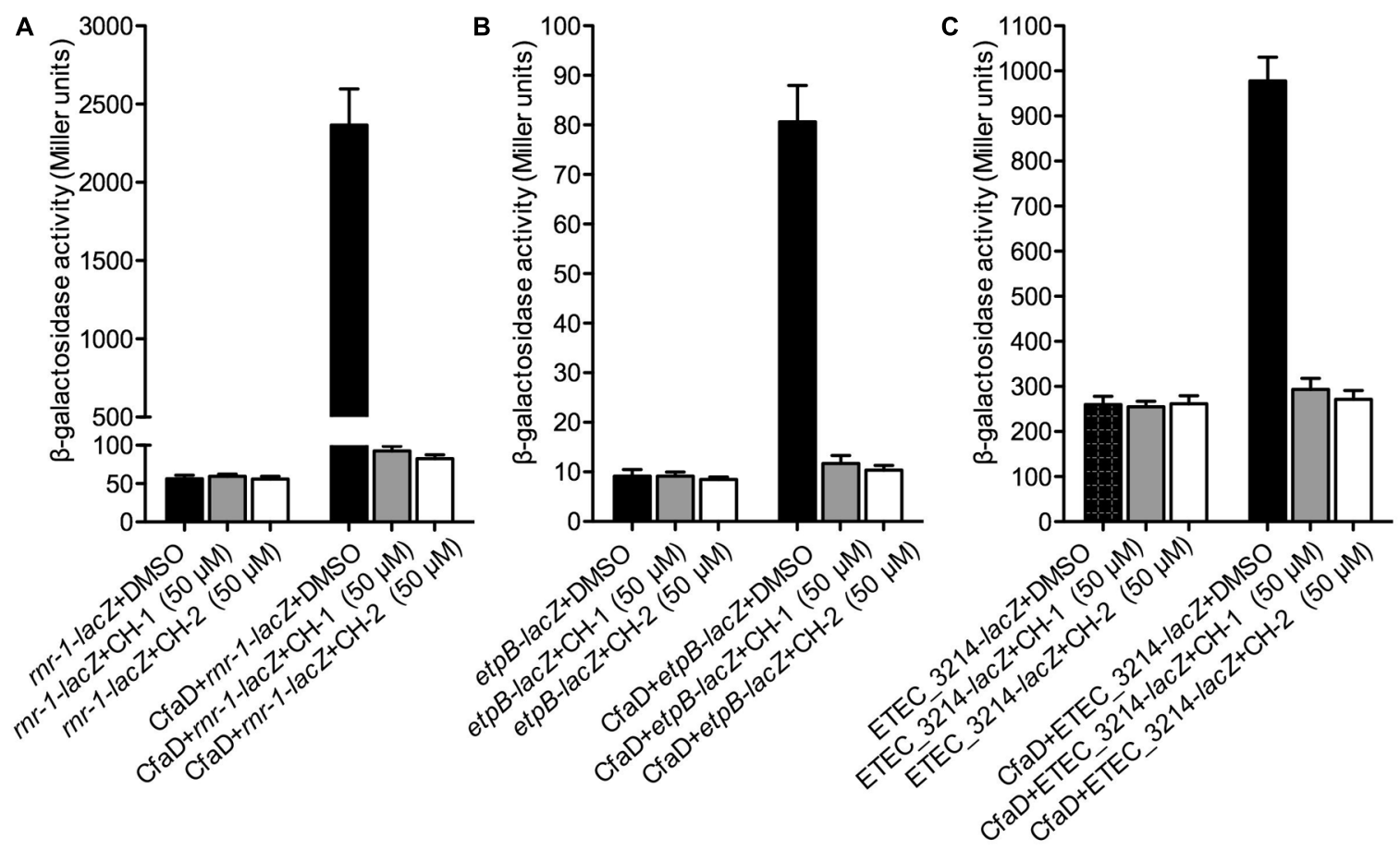

FIGURE 6 | Inhibition of $\mathrm{CH}-1$ and $\mathrm{CH}-2$ on transcription of the rnr-1, etpB, and ETEC_3214 promoters. The E. coli MC4100 strains used in this analysis all contain a pair of plasmids comprising a promoter-lacZ transcriptional fusion with either pACYC184 or pACYC184-CfaD. $\beta$-galactosidase assays were performed to evaluate the effect of $\mathrm{CH}-1$ and $\mathrm{CH}-2$ on CfaD-mediated transcriptional activation of the rnr-1 (A), etpB (B), and ETEC_3214 (C) promoters.

ETEC strain, H10407. Newly identified CfaD targets included genes encoding bacterial surface proteins (EtpA, the extracellular bridging adhesin, and Antigen 43); virulence transcriptional regulators (Rnr-1 and Rnr-2); a protein responsible for virulence plasmid transfer (TraM); and ETEC_3214, a protein of unknown function. We also demonstrated that bicarbonate ions enhance $\mathrm{CfaD}$-mediated activation of virulence gene expression.

Among the most highly upregulated genes by $\mathrm{CfaD}$ were $r n r-1$ and $r n r-2$, which are genetically linked with $c f a D$ and a pseudogene, $c f a D-2$ (which carries a frame-shift mutation in the coding region), respectively. $r n r-1$ and $r n r-2$ encode small proteins of $\sim 7.5 \mathrm{kDa}$ that repress the transcription of $c f a D$ and one of its target gene, cexE (Santiago et al., 2014). Homologs of $r n r-1$ also exist in enteroaggregative E. coli and C. rodentium, in which they repress the expression of AggR and RegA, respectively (Santiago et al., 2014). These proteins are thought to fine-tune the intracellular levels of their cognate master-regulators, $\mathrm{CfaD}$, AggR, and RegA, to allow precise expression of virulence genes in particular environments. A recent study by Santiago et al. (2016) demonstrated that these proteins are anti-activators, which bind to the central linker domain of their cognate master-regulators, disrupting their dimerization function and preventing them from binding to DNA. Our finding that CfaD strongly activates the expression of these repressors suggests that Rnr-1 and Rnr-2 are responsible for preventing runaway production of CfaD in ETEC, especially because $\mathrm{CfaD}$ activates its own transcription (Munson and Scott, 2000). In addition, given that Rnr-1 and Rnr-2 suppress virulence gene expression by downregulating $c f a D$, these two negative regulators are required during the late stages of infection to modify the transcription profile of ETEC as it exits from the host intestine to the external environment.

Another new $\mathrm{CfaD}$ target we identified was the etpBAC operon located on the pCS1 virulence plasmid of H10407 (Fleckenstein et al., 2006; Roy et al., 2009). Roy et al. (2009) have shown that EtpC is involved in glycosylation of EtpA, and that glycosylated EtpA is exported from bacterial cells by EtpB. EtpA interacts directly with highly conserved regions of flagellin (the major subunit of flagella), to form a bridge between flagella and host cell surface receptors (Roy et al., 2009). This flagellin-EtpA surface complex is critical for intestinal colonization by some ETEC strains. Our finding that the expression of the etpBAC operon is activated by $\mathrm{CfaD}$ further highlights the importance of $\mathrm{CfaD}$ in inducing the production of a variety of surface adhesins that allow ETEC to colonize its hosts.

Enterotoxigenic Escherichia coli_3214, which we also found to be directly activated by $\mathrm{CfaD}$, encodes a protein of 245 amino acids. Interestingly, ETEC_3214 is located on a genomic island, which encodes the type II secretion system and the SslE protein that are required for secretion of the heat-labile enterotoxin and the formation of biofilms by ETEC, respectively (Tauschek et al., 2002; Baldi et al., 2012). A BLAST search revealed that ETEC_3214 is also present in the uropathogenic E. coli strain, CFT073, and the avian pathogenic E. coli strain, APEC O2. In addition, a gene encoding a protein that shares $64 \%$ amino acid identity with the predicted product of ETEC_3214 was found in the plant pathogen Erwinia piriflorinigrans (CFBP5888). 
A stretch of 23 amino acids at the $\mathrm{N}$-terminus of these proteins is predicted to form a transmembrane domain ${ }^{2}$, but, the function of this protein and its relevance to ETEC virulence are not known.

Transcriptional analyses of the regulatory regions of $r n r-1$, etpBAC and ETEC_3214 identified the $\sigma^{70}$ promoters responsible for the expression of these operons (Figure 4A). Based on the consensus sequence of the CfaD-binding sites (Pilonieta et al., 2007), we identified probable CfaD-binding sites (the $\mathrm{CfaD}$ boxes) upstream of the promoters of $r n r-1$, etpBAC and ETEC_3214 (Figure 4B). Mutation of these sequences abolished CfaD-mediated activation of these three operons without affecting their basal levels of transcription (Figure 2). Furthermore, we showed using EMSA that CfaD interacts directly with regulatory regions of all three operons (Figure 3 ). The EMSA also showed that CfaD formed multiple complexes with the $r n r-1$ and $\operatorname{etp} B$ promoters but only a single complex with the ETEC_3214 promoter. This indicates the presence of more than one CfaD-binding site in the regulatory regions of $r n r-1$ and etpB. Nevertheless, our mutational analysis clearly demonstrated that the $\mathrm{CfaD}$ boxes located immediately upstream of their respective -35 sequences are responsible for activation by $\mathrm{CfaD}$ (Figures 2, 4B). The promoter regions of these operons are ATrich and predicted to be highly curved by the "bend.it" program ${ }^{3}$, supporting our suggestion that these promoters are bound and silenced by H-NS (Dorman, 2004). Given that the CfaD-binding sites are also located in the curved regions, we believe that the binding of $\mathrm{CfaD}$ counteracts the action of $\mathrm{H}-\mathrm{NS}$, leading to enhanced transcription.

Because of the central role played by $\mathrm{CfaD}$ in the global regulation of virulence gene expression in ETEC, we predicted that chemical inhibition of $\mathrm{CfaD}$ would disrupt the ability of the pathogen to cause disease. To explore this possibility we developed an in vitro assay to screen for small molecule inhibitors of $\mathrm{CfaD}$. By screening a commercial chemical library and structural analoging, we identified two compounds, $\mathrm{CH}-1$ and $\mathrm{CH}-2$, which inhibited the $\mathrm{CfaD}$-mediated activation of the cfaA, rnr-1, etpB, and ETEC_3214 promoters in E. coli K-12 and the production of the $\mathrm{CfaB}$ protein in E. coli $\mathrm{H} 10407$ (Figure 6C). These inhibitors are specific for $\mathrm{CfaD}$ as they did not inhibit the TyrR/mtr regulatory system of E. coli (Yang et al., 2013). Moreover, data from the computational docking suggested a potential inhibitor binding pocket between the dimerization and DNA-binding domains of CfaD. Although both inhibitors have a high potency in vitro, further chemical optimization is required to improve the water-solubility of these compounds before we can assess their efficacy in vivo in animals. Nevertheless, our results do prove that, like several other AraC-like virulence regulators, including ToxT, RegA, and VirF (Hung et al., 2005; Koppolu et al., 2013; Yang et al., 2013), CfaD can be exploited as a drug target for the development of novel treatments of ETEC infection.

In summary, in this study we carried out the first transcriptomic analysis of $\mathrm{CfaD}$-mediated regulation in the prototypical ETEC strain, H10407, and identified a number of previously unknown, putative virulence gene targets of CfaD.

${ }^{2}$ www.predictprotein.org/home

${ }^{3}$ http://pongor.itk.ppke.hu/dna/bend_it.html\#/bendit_intro
A

\begin{tabular}{|l|c|c|c|c|c|c|}
\hline \multirow{2}{*}{ Compound } & \multicolumn{2}{|c|}{ Site 1 } & \multicolumn{2}{c|}{ Site 2 } & \multicolumn{2}{c|}{ Site 3 } \\
\cline { 2 - 7 } & $\begin{array}{c}\text { Docking } \\
\text { score }\end{array}$ & $\begin{array}{c}\text { Cluster } \\
\%\end{array}$ & $\begin{array}{c}\text { Docking } \\
\text { score }\end{array}$ & $\begin{array}{c}\text { Cluster } \\
\%\end{array}$ & $\begin{array}{c}\text { Docking } \\
\text { score }\end{array}$ & $\begin{array}{c}\text { Cluster } \\
\%\end{array}$ \\
\hline $\mathrm{CH}-1$ & 7.44 & 0 & 5.48 & 70 & 5.19 & 35 \\
\hline $\mathrm{CH}-2$ & 8.09 & 0 & 7.50 & 90 & 5.43 & 60 \\
\hline
\end{tabular}
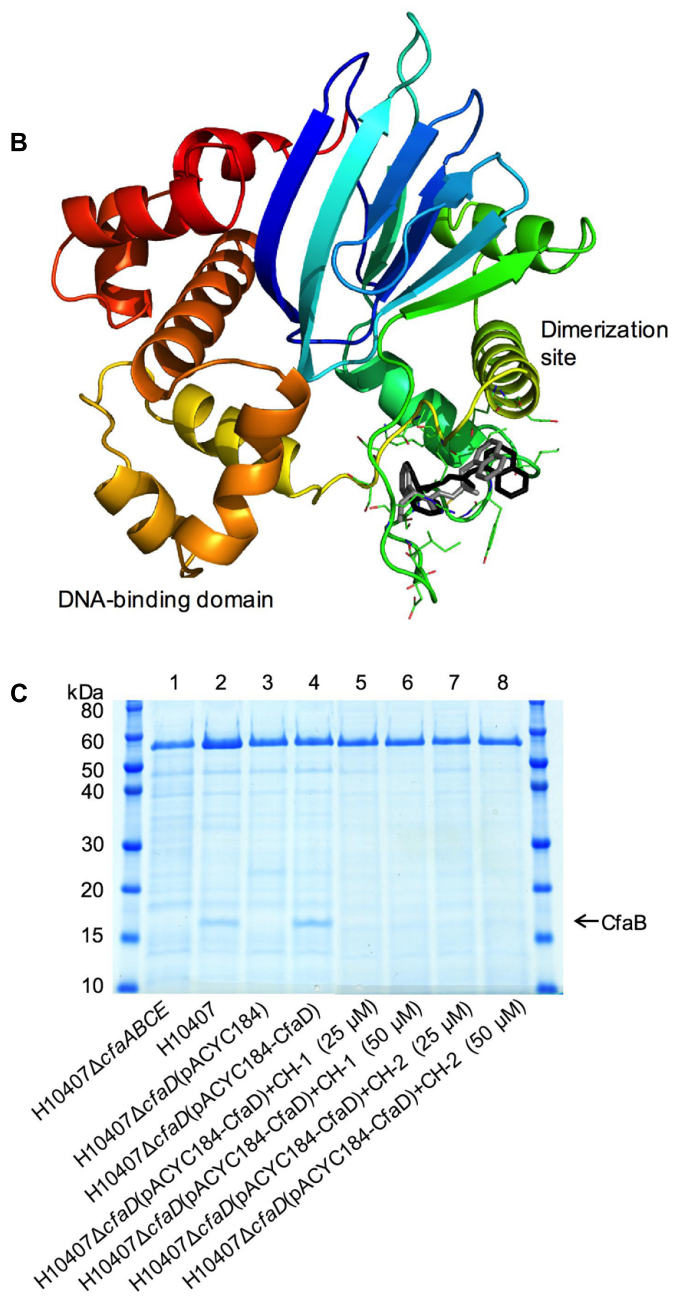

FIGURE 7 | Characterization of the interaction of $\mathrm{CH}-1$ and $\mathrm{CH}-2$ with $\mathrm{CfaD}$ and confirmation of the inhibitory activity of $\mathrm{CH}-1$ and $\mathrm{CH}-2$ on the production of the CFAll fimbriae in E. coli $\mathrm{H} 10407$. (A) Table showing the docking scores and clustering values for the top docked solutions of $\mathrm{CH}-1$ and $\mathrm{CH}-2$. (B) A docking model showing the proposed interaction of $\mathrm{CH}-1$ (black) and $\mathrm{CH}-2$ (gray) with the $\mathrm{CfaD}$ protein (ribbon). The homology model of $\mathrm{CfaD}$ was generated from the crystal structure of ToxT of Vibrio cholerae and is colored rainbow from $\mathrm{N}$-terminus (blue) to $\mathrm{C}$-terminus (red). The proposed dimerization site (green helix) and DNA-binding domain (red and orange helices) are labeled. (C) SDS-PAGE analysis of heat-extracted surface proteins from E. coli $\mathrm{H} 10407$ and its derivatives demonstrates that the CfaD-dependent production of the major subunit of the CFA/I fimbriae (CfaB) can be inhibited by the presence of $\mathrm{CH}-1$ and $\mathrm{CH}-2(25 \mu \mathrm{M}$ or $50 \mu \mathrm{M})$ in growth medium.

Molecular characterization of some of these target operons identified the promoters and operators that are responsible for CfaD-mediated activation of gene expression. Furthermore, transcriptional analysis demonstrated that the gut-associated 
chemical, sodium bicarbonate, acts as a cofactor to enhance expression of the virulence genes controlled by $\mathrm{CfaD}$. The critical importance of $\mathrm{CfaD}$ in the control of ETEC virulence makes it a potential target for new types of drugs that could be used to combat ETEC infections (Yang et al., 2013). In this regard, we identified two small-molecule compounds that specifically inhibited the regulatory function of $\mathrm{CfaD}$, demonstrating that this regulator is a suitable target for the development of drugs to combat ETEC infection.

\section{AUTHOR CONTRIBUTIONS}

$\mathrm{CH}, \mathrm{JY}, \mathrm{MT}$, and RR-B designed and performed most of the experiments and contributed to the analysis and interpretation of data. DH, KA, QC, and JH carried out some experiments. $\mathrm{MT}, \mathrm{JH}$, and MP dealt with the preparation of figures, drafting the work and revising it critically. The manuscript was written by $\mathrm{CH}, \mathrm{JY}, \mathrm{MT}$, and RR-B and reviewed by all authors before submission.

\section{REFERENCES}

Abuaita, B. H., and Withey, J. H. (2009). Bicarbonate Induces Vibrio cholerae virulence gene expression by enhancing ToxT activity. Infect. Immun. 77, 4111-4120. doi: 10.1128/IAI.00409-09

Al-Abri, S. S., Beeching, N. J., and Nye, F. J. (2005). Traveller's diarrhoea. Lancet Infect. Dis. 5, 349-360. doi: 10.1016/S1473-3099(05)70139-0

Baldi, D. L., Higginson, E. E., Hocking, D. M., Praszkier, J., Cavaliere, R., James, C. E., et al. (2012). The type II secretion system and its ubiquitous lipoprotein substrate, SslE, are required for biofilm formation and virulence of enteropathogenic Escherichia coli. Infect. Immun. 80, 2042-2052. doi: 10.1128/ IAI.06160-11

Bodero, M. D., and Munson, G. P. (2016). The virulence regulator Rns activates the expression of CS14 pili. Genes 7:120. doi: 10.3390/genes7120120

Bodero, M. D., Pilonieta, M. C., and Munson, G. P. (2007). Repression of the inner membrane lipoprotein NlpA by Rns in enterotoxigenic Escherichia coli. J. Bacteriol. 189, 1627-1632. doi: 10.1128/JB.01714-06

Bradford, M. M. (1976). A rapid and sensitive method for the quantitation of microgram quantities of protein utilizing the principle of proteindye binding. Anal. Biochem. 72, 248-254. doi: 10.1016/0003-2697(76) 90527-3

Caron, J., Coffield, L. M., and Scott, J. R. (1989). A plasmid-encoded regulatory gene, rns, required for expression of the CS1 and CS2 adhesins of enterotoxigenic Escherichia coli. Proc. Natl. Acad. Sci. U.S.A. 86, 963-967. doi: 10.1073 /pnas.86.3.963

Caron, J., and Scott, J. R. (1990). A rns-like regulatory gene for colonization factor antigen I (CFA/I) that controls expression of CFA/I pilin. Infect. Immun. 58, 874-878.

Casadaban, M. J. (1976). Transposition and fusion of the lac genes to selected promoters in Escherichia coli using bacteriophage lambda and Mu. J. Mol. Biol. 104, 541-555. doi: 10.1016/0022-2836(76)90119-4

Chang, A. C., and Cohen, S. N. (1978). Construction and characterization of amplifiable multicopy DNA cloning vehicles derived from the P15A cryptic miniplasmid. J. Bacteriol. 134, 1141-1156.

Crooks, G. E., Hon, G., Chandonia, J. M., and Brenner, S. E. (2004). WebLogo: a sequence logo generator. Genome Res. 14, 1188-1190. doi: 10.1101/gr.849004

Crossman, L. C., Chaudhuri, R. R., Beatson, S. A., Wells, T. J., Desvaux, M. Cunningham, A. F., et al. (2010). A commensal gone bad: complete genome sequence of the prototypical enterotoxigenic Escherichia coli strain H10407. J. Bacteriol. 192, 5822-5831. doi: 10.1128/JB.00710-10

\section{FUNDING}

This work was supported by grants from the Australian National Health and Medical Research Council (NHMRC). $\mathrm{CH}$ is a recipient of an Australian Postgraduate Award. JH is a 5point Foundation Christine Martin Fellow. MP is an NHMRC Senior Principal Research Fellow. Infrastructure support from the NHMRC Independent Research Institutes Infrastructure Support Scheme and the Victorian State Government Operational Infrastructure Support Program to St. Vincent's Institute are gratefully acknowledged.

\section{SUPPLEMENTARY MATERIAL}

The Supplementary Material for this article can be found online at: http://journal.frontiersin.org/article/10.3389/fmicb. 2017.01525/full\#supplementary-material

TABLE S1 | RNAseq data generated in this study. The genes in $\mathrm{H} 10407$ that are differentially expressed in CfaD-minus and CfaD-plus backgrounds in the presence or absence of sodium bicarbonate.

Croxen, M. A., and Finlay, B. B. (2010). Molecular mechanisms of Escherichia coli pathogenicity. Nat. Rev. Microbiol. 8, 26-38. doi: 10.1038/nrmicro2265

Datsenko, K. A., and Wanner, B. L. (2000). One-step inactivation of chromosomal genes in Escherichia coli K-12 using PCR products. Proc. Natl. Acad. Sci. U.S.A. 97, 6640-6645. doi: 10.1073/pnas.120163297

de la Cruz, F., Frost, L. S., Meyer, R. J., and Zechner, E. L. (2010). Conjugative DNA metabolism in Gram-negative bacteria. FEMS Microbiol. Rev. 34, 18-40. doi: 10.1111/j.1574-6976.2009.00195.x

DiRita, V. J., Parsot, C., Jander, G., and Mekalanos, J. J. (1991). Regulatory cascade controls virulence in Vibrio cholerae. Proc. Natl. Acad. Sci. U.S.A. 88, 5403-5407. doi: $10.1073 /$ pnas.88.12.5403

Dorman, C. J. (1992). The VirF protein from Shigella flexneri is a member of the AraC transcription factor superfamily and is highly homologous to Rns, a positive regulator of virulence genes in enterotoxigenic Escherichia coli. Mol. Microbiol. 6:1575. doi: 10.1111/j.1365-2958.1992.tb00879.x

Dorman, C. J. (2004). H-NS: a universal regulator for a dynamic genome. Nat. Rev. Microbiol. 2, 391-400. doi: 10.1038/nrmicro883

Dorman, C. J. (2007). H-NS, the genome sentinel. Nat. Rev. Microbiol. 5, 157-161. doi: $10.1038 /$ nrmicro 1598

Evans, D. G., Evans, D. J. Jr., Clegg, S., and Pauley, J. A. (1979). Purification and characterization of the CFA/I antigen of enterotoxigenic Escherichia coli. Infect. Immun. 25, 738-748.

Fleckenstein, J. M., Hardwidge, P. R., Munson, G. P., Rasko, D. A., Sommerfelt, H., and Steinsland, H. (2010). Molecular mechanisms of enterotoxigenic Escherichia coli infection. Microbes Infect. 12, 89-98. doi: 10.1016/j.micinf.2009. 10.002

Fleckenstein, J. M., Roy, K., Fischer, J. F., and Burkitt, M. (2006). Identification of a two-partner secretion locus of enterotoxigenic Escherichia coli. Infect. Immun. 74, 2245-2258. doi: 10.1128/IAI.74.4.2245-2258.2006

Gaastra, W., and Svennerholm, A. M. (1996). Colonization factors of human enterotoxigenic Escherichia coli (ETEC). Trends Microbiol. 4, 444-452. doi: 10.1016/0966-842X(96)10068-8

Gallegos, M. T., Schleif, R., Bairoch, A., Hofmann, K., and Ramos, J. L. (1997). Arac/XylS family of transcriptional regulators. Microbiol. Mol. Biol. Rev. 61, 393-410.

Hung, D. T., Shakhnovich, E. A., Pierson, E., and Mekalanos, J. J. (2005). Smallmolecule inhibitor of Vibrio cholerae virulence and intestinal colonization. Science 310, 670-674. doi: 10.1126/science.1116739

Johnson, B. K., Scholz, M. B., Teal, T. K., and Abramovitch, R. B. (2016). SPARTA: simple program for automated reference-based bacterial RNA-seq 
transcriptome analysis. BMC Bioinformatics 17:66. doi: 10.1186/s12859-0160923-y

Koppolu, V., Osaka, I., Skredenske, J. M., Kettle, B., Hefty, P. S., Li, J., et al. (2013). Small-molecule inhibitor of the Shigella flexneri master virulence regulator VirF. Infect. Immun. 81, 4220-4231. doi: 10.1128/IAI.00919-13

Kotloff, K. L., Nataro, J. P., Blackwelder, W. C., Nasrin, D., Farag, T. H., Panchalingam, S., et al. (2013). Burden and aetiology of diarrhoeal disease in infants and young children in developing countries (the Global Enteric Multicenter Study, GEMS): a prospective, case-control study. Lancet 382, 209-222. doi: 10.1016/S0140-6736(13)60844-2

Langmead, B., Trapnell, C., Pop, M., and Salzberg, S. L. (2009). Ultrafast and memory-efficient alignment of short DNA sequences to the human genome. Genome Biol. 10:R25. doi: 10.1186/gb-2009-10-3-r25

Laskowski, R. A., MacArthur, M. W., Moss, D. S., and Thornton, J. M. (1993). PROCHECK: a program to check the stereochemical quality of protein structures. J. App. Cryst. 26, 283-291. doi: 10.1107/S0021889892009944

Li, H., Handsaker, B., Wysoker, A., Fennell, T., Ruan, J., Homer, N., et al. (2009). The sequence alignment/map format and SAMtools. Bioinformatics 25 , 2078-2079. doi: 10.1093/bioinformatics/btp352

Lohse, M., Bolger, A. M., Nagel, A., Fernie, A. R., Lunn, J. E., Stitt, M., et al. (2012). RobiNA: a user-friendly, integrated software solution for RNA-Seqbased transcriptomics. Nucleic Acids Res. 40, W622-W627. doi: 10.1093/nar/ gks540

Lowden, M. J., Skorupski, K., Pellegrini, M., Chiorazzo, M. G., Taylor, R. K., and Kull, F. J. (2010). Structure of Vibrio cholerae ToxT reveals a mechanism for fatty acid regulation of virulence genes. Proc. Natl. Acad. Sci. U.S.A. 107, 2860-2865. doi: 10.1073/pnas.0915021107

Miller, J. H. (1974). Experiments in Molecular Genetics. Plainview, NY: Cold Spring Harbor Laboratory Press.

Munson, G. P., and Scott, J. R. (1999). Binding site recognition by Rns, a virulence regulator in the AraC family. J. Bacteriol. 181, 2110-2117.

Munson, G. P., and Scott, J. R. (2000). Rns, a virulence regulator within the AraC family, requires binding sites upstream and downstream of its own promoter to function as an activator. Mol. Microbiol. 36, 1391-1402. doi: 10.1046/j.13652958.2000.01957.x

Nataro, J. P., Yikang, D., Yingkang, D., and Walker, K. (1994). AggR, a transcriptional activator of Aggregative Adherence Fimbria I expression in enteroaggregative Escherichia coli. J. Bacteriol. 176, 4691-4699. doi: 10.1128/jb. 176.15.4691-4699.1994

Owen, P., Caffrey, P., and Josefsson, L. G. (1987). Identification and partial characterization of a novel bipartite protein antigen associated with the outer membrane of Escherichia coli. J. Bacteriol. 169, 3770-3777. doi: 10.1128/jb.169. 8.3770-3777.1987

Paschke, C., Apelt, N., Fleischmann, E., Perona, P., Walentiny, C., Loscher, T., et al. (2011). Controlled study on enteropathogens in travellers returning from the tropics with and without diarrhoea. Clin. Microbiol. Infect. 17, 1194-1200. doi: 10.1111/j.1469-0691.2010.03414.x

Pilonieta, M. C., Bodero, M. D., and Munson, G. P. (2007). CfaD-dependent expression of a novel extracytoplasmic protein from enterotoxigenic Escherichia coli. J. Bacteriol. 189, 5060-5067. doi: 10.1128/JB.00131-07

Roy, K., Hilliard, G. M., Hamilton, D. J., Luo, J., Ostmann, M. M., and Fleckenstein, J. M. (2009). Enterotoxigenic Escherichia coli EtpA mediates adhesion between flagella and host cells. Nature 457, 594-598. doi: 10.1038/nature 07568

Sali, A., Potterton, L., Yuan, F., Van Vlijmen, H., and Karplus, M. (1995). Evaluation of comparative protein modeling by MODELLER. Proteins 23, 318-326. doi: 10.1002/prot.340230306
Santiago, A. E., Ruiz-Perez, F., Jo, N. Y., Vijayakumar, V., Gong, M. Q., and Nataro, J. P. (2014). A large family of antivirulence regulators modulates the effects of transcriptional activators in Gram-negative pathogenic bacteria. PLoS Pathog. 10:e1004153. doi: 10.1371/journal.ppat.1004153

Santiago, A. E., Yan, M. B., Tran, M., Wright, N., Luzader, D. H., Kendall, M. M., et al. (2016). A large family of anti-activators accompanying XylS/AraC family regulatory proteins. Mol. Microbiol. 101, 314-332. doi: 10.1111/mmi. 13392

Skerman, F. J., Formal, S. B., and Falkow, S. (1972). Plasmid-associated enterotoxin production in a strain of Escherichia coli isolated from humans. Infect. Immun. 5, 622-624.

Soding, J., Biegert, A., and Lupas, A. N. (2005). The HHpred interactive server for protein homology detection and structure prediction. Nucleic Acids Res. 33, W244-W248. doi: 10.1093/nar/gki408

Song, C. S., Jung, M. H., Chen, S., and Chatterjee, B. (1997). A rapid one-step procedure for preparation of $\mathrm{G}$ plus $\mathrm{A}$ sequence markers by acid-induced apurinization and DNA cleavage. Tech. Tips Online 2, 42-44. doi: 10.1016/ S1366-2120(08)70028-X

Tan, A., Yang, J., Tauschek, M., Praszkier, J., and Robins-Browne, R. M. (2011). Autogenous transcriptional regulation of the regA gene, encoding an AraCLike, essential virulence regulator in Citrobacter rodentium. J. Bacteriol. 193, 1777-1782. doi: 10.1128/JB.01224-10

Tauschek, M., Gorrell, R. J., Strugnell, R. A., and Robins-Browne, R. M. (2002). Identification of a protein secretory pathway for the secretion of heat-labile enterotoxin by an enterotoxigenic strain of Escherichia coli. Proc. Natl. Acad. Sci. U.S.A. 99, 7066-7071. doi: 10.1073/pnas.092152899

Yang, J., Dogovski, C., Hocking, D., Tauschek, M., Perugini, M., and RobinsBrowne, R. M. (2009). Bicarbonate-mediated stimulation of RegA, the global virulence regulator from Citrobacter rodentium. J. Mol. Biol. 394, 591-599. doi: 10.1016/j.jmb.2009.10.033

Yang, J., Ganesan, S., Sarsero, J., and Pittard, A. J. (1993). A genetic analysis of various functions of the TyrR protein of Escherichia coli. J. Bacteriol. 175, 1767-1776. doi: 10.1128/jb.175.6.1767-1776.1993

Yang, J., Hocking, D. M., Cheng, C., Dogovski, C., Perugini, M. A., Holien, J. K., et al. (2013). Disarming bacterial virulence through chemical inhibition of the DNA binding domain of an AraC-like transcriptional activator protein. J. Biol. Chem. 288, 31115-31126. doi: 10.1074/jbc.M113. 503912

Yang, J., Hwang, J. S., Camakaris, H., Irawaty, W., Ishihama, A., and Pittard, J. (2004). Mode of action of the TyrR protein: repression and activation of the tyrP promoter of Escherichia coli. Mol. Microbiol. 52, 243-256. doi: 10.1111/j. 1365-2958.2003.03965.x

Yang, J., Tauschek, M., and Robins-Browne, R. M. (2011). Control of bacterial virulence by AraC-like regulators that respond to chemical signals. Trends Microbiol. 19, 128-135. doi: 10.1016/j.tim.2010.12.001

Conflict of Interest Statement: The authors declare that the research was conducted in the absence of any commercial or financial relationships that could be construed as a potential conflict of interest.

Copyright (C) 2017 Hodson, Yang, Hocking, Azzopardi, Chen, Holien, Parker, Tauschek and Robins-Browne. This is an open-access article distributed under the terms of the Creative Commons Attribution License (CC BY). The use, distribution or reproduction in other forums is permitted, provided the original author(s) or licensor are credited and that the original publication in this journal is cited, in accordance with accepted academic practice. No use, distribution or reproduction is permitted which does not comply with these terms. 